\title{
Scar formation after drug-induced cochlear insult
}

\author{
Yehoash Raphael and Richard A. Altschuler \\ Kresge Hearing Research Institute, University of Michigan Medical School, Ann Arbor, Michigan, U.S.A.
}

(Received 12 April 1990; accepted 25 July 1990)

\begin{abstract}
Structural and molecular changes in the guinea pig organ of Corti were studied using hislochemistry and electron microscopy in the course of drug-induced hair cell degeneration. Actin filaments disappear from the cuticular plate and the stereocilia. An actin-rich bridge appears in the apical region of dying hair cells. Two supporting cells form a scar for a given hair cell. The supporting cells expand and invade the spaces of Nuel and then the region previously occupied by the hair cell. The scar region becomes cytokeratin-labeled. In this study, the apical domain of the hair cell is the last part of the cell to degenerate. Hair cell degeneration coincides temporally with scar formation. We define the resulting scar as a 'type I' scar. The results provide preliminary information about the molecular composition of the type I scar and suggest a structural basis for the dynamics of scar formation.
\end{abstract}

Ototoxicity; Phalangeal scar; Actin; Cytokeratins

\section{Introduction}

Hair cell degeneration and scar formation after various types of insults has been extensively studied (Engström et al., 1966; Bohne, 1976; Hawkins, 1976). After most types of insults to the cochlea, hair cell degeneration results in nonsensory cells replacing the lost hair cells and forming a 'phalangeal scar' (PS). The PS may be essential to prevent further damage to the cochlea and to retain the function of the remaining cells, albeit in a pathophysiological condition. Humans and other mammals hear throughout most of their life despite progressive hair cell loss, suggesting that scar formation is effective.

This study was designed to assess the molecular structure of scars in the reticular lamina after injury, and the mechanism of their formation. We studied the spatial and temporal changes of cells in the outer hair cell region during scar formation. Hair cell loss was induced by kanamycin and

Correspondence to: Yehoash Raphael, Kresge Hearing Research Institutc, 1301 East Ann Street, Ann Arbor, MI 481090506, U.S.A. FAX: (313) 764-0014. ethacrynic acid. The organ of Corti was analyzed after various time intervals following insult to observe changes in shape, size or location of various cell types during PS formation. The results reported here cover several stages leading to what we define as a 'type I' scar, in which one or more outer hair cells are replaced by supporting cells, but the organ of Corti does not collapse.

Investigation at the molecular level was performed to better understand interactions between various cell types which participate in the scarring process and to understand how their shape, size and location is modulated during the scarring process. Specifically, we investigated the modification of junctional elements and of various cytoskeletal proteins known to play a role in cell-cell interaction and/or scarring in other tissues. Actin was studied because it is a major cytoskeletal protein in hair cells (Flock and Cheung, 1977; Slepecky and Chamberlain 1982; Tilney and Saunders, 1982), it is involved in cell movements (Small et al., 1982; Geiger et al., 1985a) and it is present in adherens junctional complexes (Geiger et al., 1985b). The distribution of intermediate filaments (IFs) was studied because the expression of these proteins is modulated during differentia- 
tion as well as during PS formation in various tissues (Franke et al., 1982; Wilson et al., 1984). In addition, IFs are thought to provide mechanical stability for cells and tissues (Osborn et al., 1982; Cowin et al., 1985; Klymkowski et al., 1989). Two types of IFs have been observed in epithelial cells in the organ of Corti: cytokeratins and vimentin (Anniko et al., 1987; Raphael et al., 1987; Raphael and Oesterle, 1989). Because cytokeratin expression in the organ of Corti is restricted to nonsensory cells (Raphael et al., 1987), cytokeratins can serve as a valuable marker for the identification of supporting cells in damaged regions of the sensory epithelium.

Knowledge of the scarring mechanism may provide information about the repair mechanism that maintains the anatomical and functional integrity of the auditory organ. In addition, it may enhance our understanding of the following questions:

1. Is the signal which initiates scar formation related to the signal which determines whether a hair cell will recover from an insult or will degenerate?

2. How does the scar in some cases become unstable, leading to further degeneration in the organ of Corti?

3. Why do mammalian hair cells fail to regenerate while non-mammalian hair cells can do so?

\section{Materials and Methods}

Twenty-two young pigmented guinea pigs were injected with kanamycin $(400 \mathrm{mg} / \mathrm{kg}, \mathrm{sc})$ followed $2 \mathrm{~h}$ later by ethacrynic acid $(40 \mathrm{mg} / \mathrm{kg}$, iv). This drug regime has been shown to reliably produce profound deafness in guinea pigs (Webster and Webster, 1981). Five non-treated guinea pigs served as controls. Survival times after administration of the drugs were 3,5 or 9 h, 1 , or 14 weeks, 6 or 9 months. For immunohistochemistry, animals were anesthetized and systemically perfused with a solution containing $2 \%$ paraformaldehyde in 0.1 $\mathrm{M}$ phosphate buffer, $\mathrm{pH}$ 7.4. After fixation, the surface of the organ of Corti was exposed by removing the otic capsule and tectorial membrane, and the cochlea was immersed in $0.3 \%$ Triton $\mathrm{X}-100$ for $5 \mathrm{~min}$. For immunocytochemistry, the whole cochlea was incubated in primary antibody for $1 \mathrm{~h}$, washed for $20 \mathrm{~min}$, incubated for $45 \mathrm{~min}$ in the second antibody, rinsed again, dissected in half-turns and mounted in a glycerol-PBS solution. The following immunoreagents were used: (a) Monoclonal anti-cytokeratin pan antibody (Boehringer Mannheim) which binds to an epitope common to all types of cytokeratins. (b) Monoclonal anti-vimentin antibodies V9 and 3B4 (Boehringer Mannheim). (c) Secondary antibodies: rhodamin-conjugated goat anti-mouse IgG or IgM (Sigma and Boehringer Mannheim). FITCconjugated phallacidin or phalloidin (Molecular Probes, Oregon) was diluted 1:50 and used alone or together with the secondary antibody to double-label for actin.

Comparative observations along the cochlear duct were performed to determine differences in the pattern of PS formation among different rows of hair cells and among different turns of the cochlear duct. Tissue preparations were examined and photographed using a Leitz Orthoplan microscope equipped for epifluorescence using $16 \times$, $50 \times$ oil and $100 \times$ oil objectives. Photomicrographs were taken on Kodak Tmax 400 film exposed at 1600 ASA and processed in Tmax developer.

To prepare the tissue for scanning (SEM) and transmission (TEM) electron microscopy, animals were perfused with $2 \%$ paraformaldehyde and $2.5 \%$ glutaraldehyde in $0.15 \mathrm{M}$ cacodylate buffer, $\mathrm{pH}$ 7.4. The bullae were opened, otic capsules removed and the cochleae immersed in the same fixative for $2 \mathrm{~h}$ at room temperature. TEM specimens were postfixed in $1 \%$ osmium tetroxide, decalcified in $3 \%$ EDTA containing $1.25 \%$ glutaraldehyde for 2 weeks, dehydrated in ethanols and embedded in Epon. Thin sections were cut on a Reichert-Jung Ultracut $E$ ultramicrotome, stained with uranyl acetate and lead citrate, and examined in a Jeol JEM 1200 EX electron microscope.

Consecutive light microscope (LM) sections were analyzed to determine the condition of the tissue. Four-micron sections were stained with either toluidine blue or paragon stain and examined with a Leitz Dialux microscope. SEM specimens were postfixed in $1 \%$ osmium tetroxide for $20 \mathrm{~min}$, dehydrated in ethanol, critical-point 
dried in $\mathrm{CO}_{2}$, sputter-coated with gold and analysed in an Amray 1000B scanning electron microscope.

\section{Results}

The use of histochemically processed surface preparations to detect changes in the distribution of microfilaments and IFs proved useful for identifying cells in early stages of degeneration. Changes in the distribution of actin could be observed within a few hours after drug administration in phalloidin-labeled whole-mounts of the organ of Corti (Fig. 2). In non-treated animals (Fig. 1), phalloidin staining for actin was intense in the stereocilia and cuticular plate of hair cells and in the belt of adherens junctions which connect adjacent sensory and supporting cells to form the mosaic of the reticular lamina.

Three hours after drug administration, we could observe several changes in the tissue. A substantial reduction in the intensity of actin labeling was seen in the stereocilia and the cuticular plate, and a moderate reduction in staining was observed in the junctional belt of several hair cells (Fig. 2A). TEM analysis of tissue at this stage revealed supporting cells occupying the fluid spaces around the hair cells (Fig. 4A). The lateral membranes of supporting cells and hair cells were in contact. The apical (luminal) membrane of both hair cells and
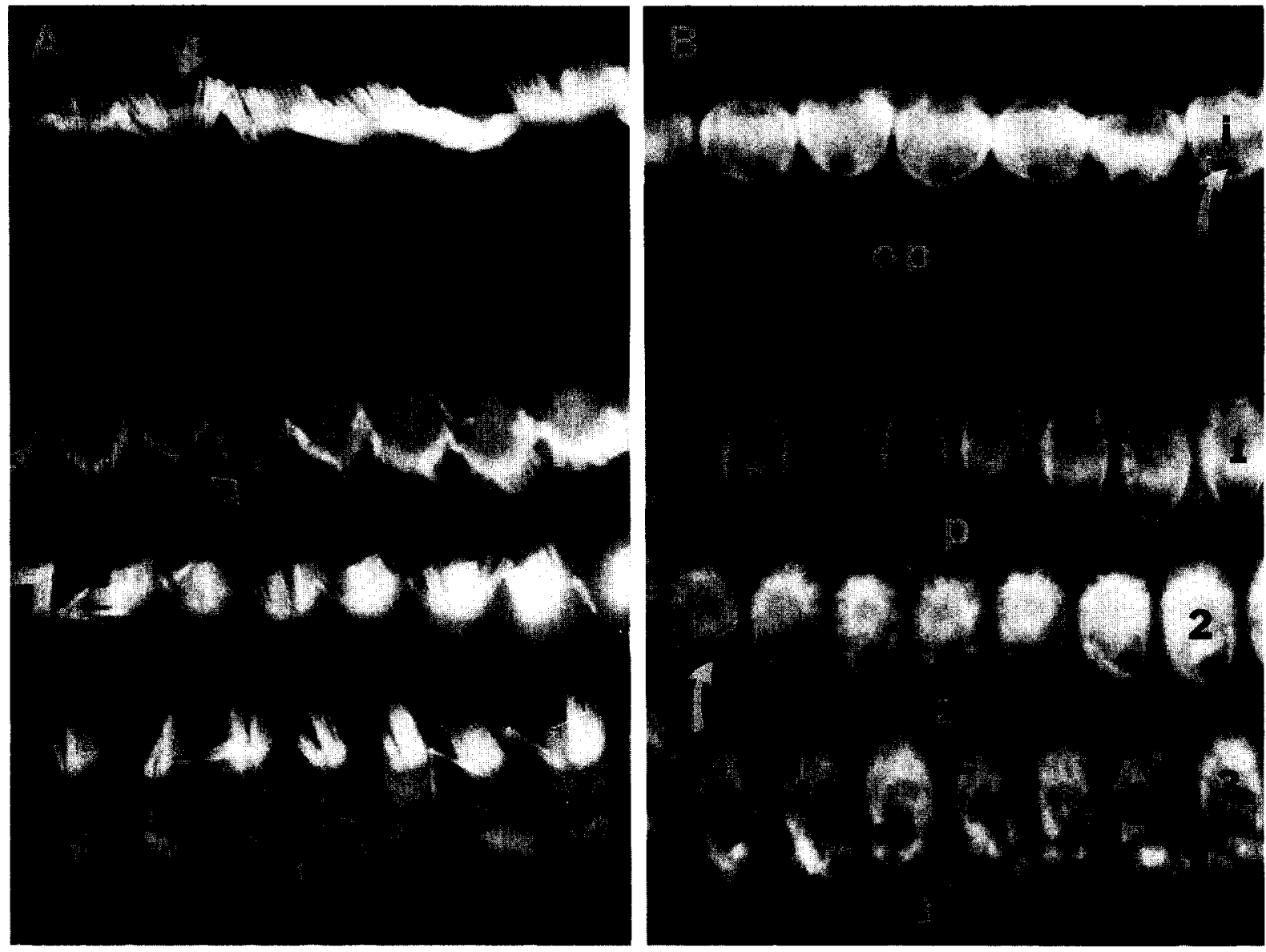

Fig. 1. Phalloidin-labeled whole-mounts showing distribution of actin in normal organ of Corti. (A) Focus on stereocilia of inner hair cells (arrow) and outer hair cells (arrow-frame). (B) Focus on reticular lamina, showing cuticular plates and adherens junctions in inner (i) and outer (black 1, 2, 3) hair cells. op-, inner pillar cell, p-, outer pillar cell, 1,2,3 white-1st, 2nd and 3rd row Deiters cells. Note lack of actin label in cuticle-free region of hair cells (arrows). Magnification: $\times 1100$. 

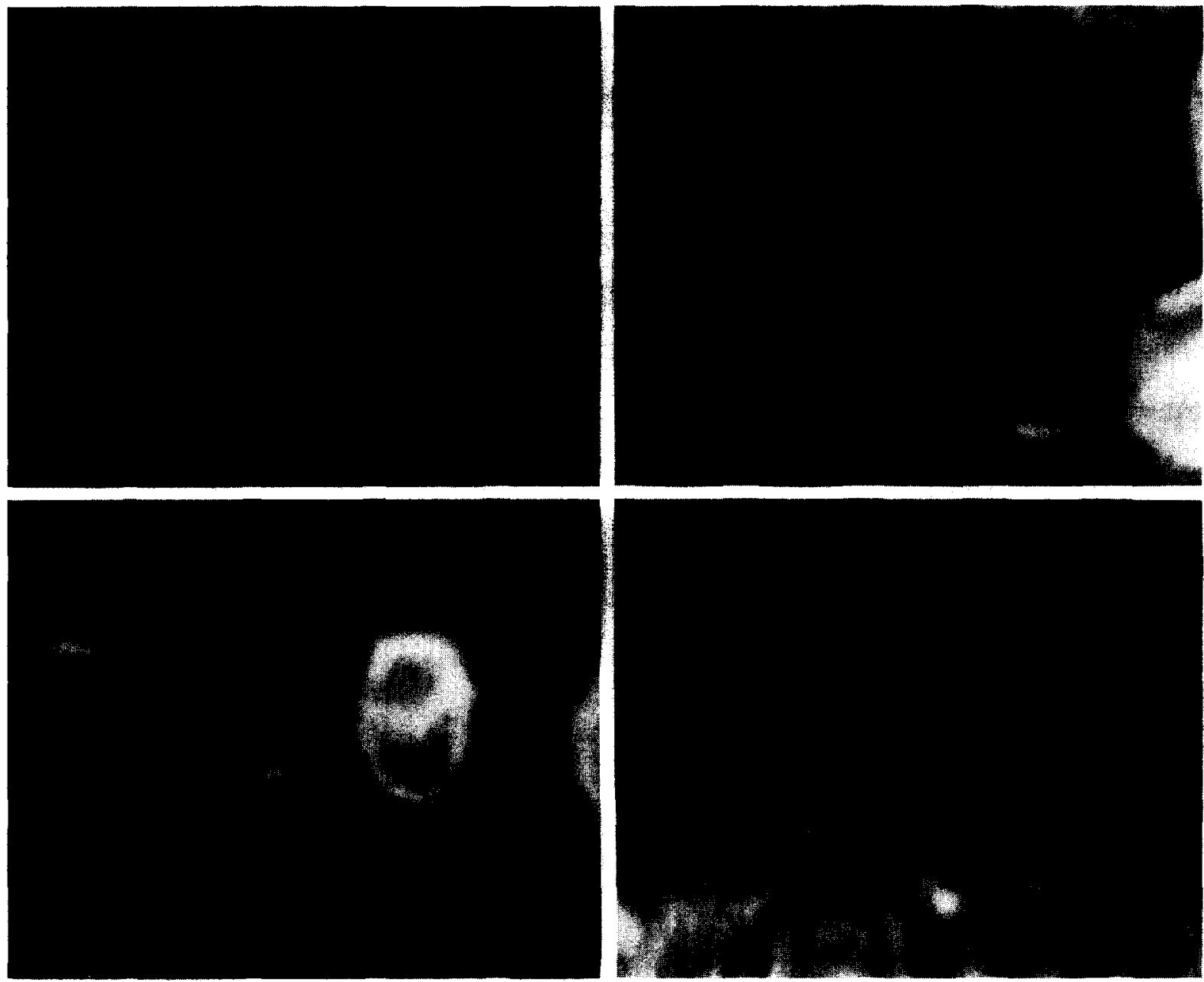

Fig. 2. Phalloidin-labeled whole-mounts at 4 stages of scar formation. (A) Reduced intensity of actin specific staining in region of cuticular plate and stereocilia (arrow) three hours after drug administration. (B) Five hours after treatment, actin 'bridge' spans apical area of injured hair cells (arrows). The bridge contains 2 actin-bands (lower arrow). The cuticle-free region remains actin-free (arrow-frame). (C) Intensity of actin label in bridge is increased (arrow). Continuity of actin in adherens junction belt is interrupted (arrow frame). (D) Type I scar replacing 3rd row outer hair cell nine hours after drug administration. Actin specific label is in bridge

(arrow) and in adherens junction of two Deiters cells forming the scar. Magnification: $\mathrm{A}$ and $\mathrm{D}=\times 1300 ; \mathrm{B}$ and $\mathrm{C}=\times 1800$.

supporting cells appeared intact, but the cytoplasm was less dense than normal and contained several vacuoles. The stereocilia were densely stained and the regular pattern of microfilament organization was absent. The dense material in the cuticular plate had partially disappeared.

Examination of LM sections three hours after the treatment showed expansion in volume of a 2nd row Deiters cells while hair cells appeared relatively normal (Fig. 3A). In other LM sections, the basal or middle portions of outer hair cells were missing, and expanded supporting cells filled the fluid spaces of Nuel (Fig. 3B). The apical region of outer hair cells appeared normal at this stage.

Five hours after drug administration, further changes were seen in the distribution of cytoskeletal proteins in areas of injury. Whole-mounts labeled for actin revealed in the region of the forming scar an actin-rich structure which we term a 'bridge'. The bridge was spatially oriented in a radial direction, perpendicular to the axis of the 

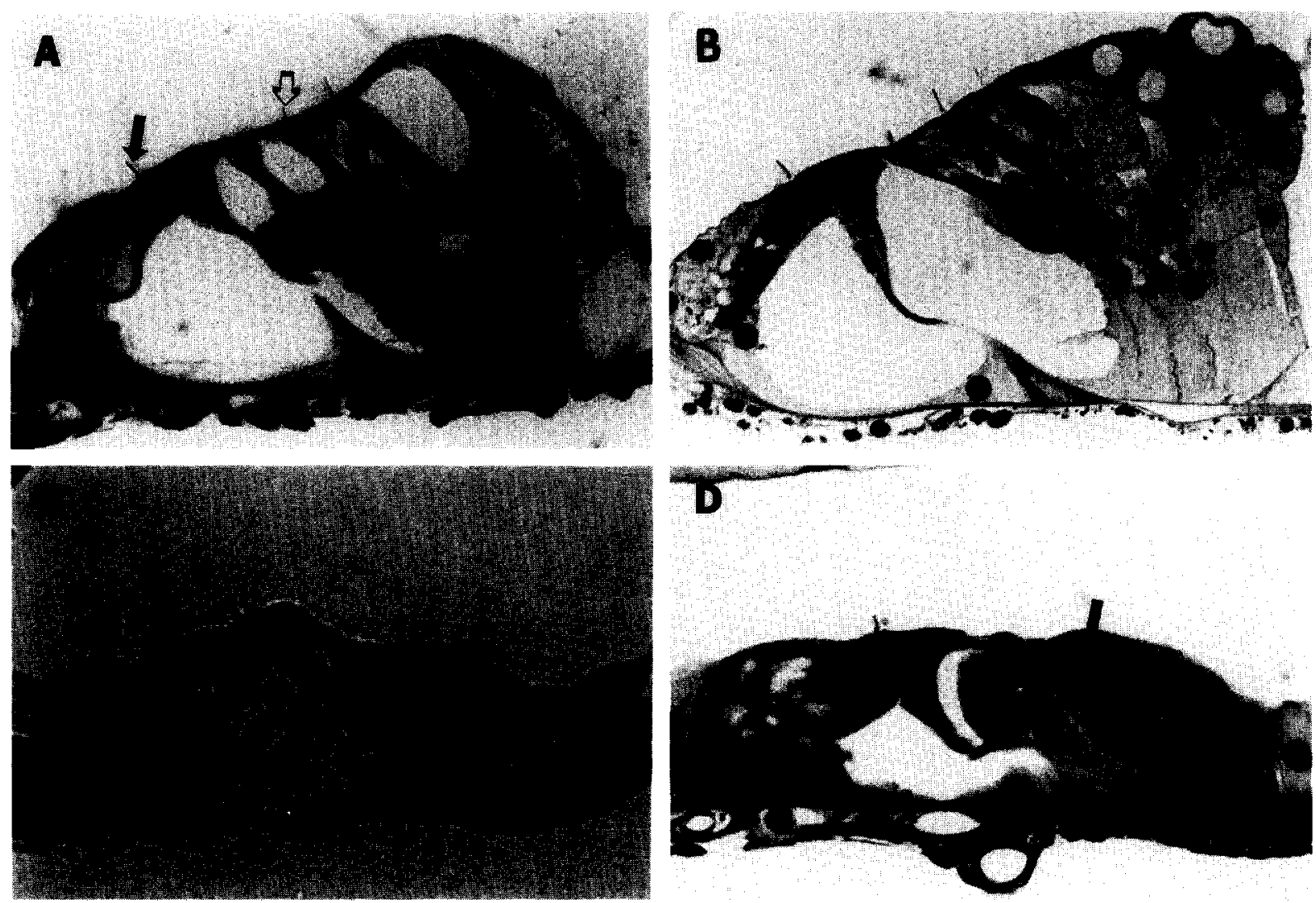

Fig. 3. Mid-modiolar LM cross sections of organ of Corti. (A) First signs of scar formation at LM level are expansion of phalangeal process of a supporting cell, while outer hair cells (arrow-frame) and inner hair cells (arrow) appear normal. (B) Three hours after drug administration, basal area of 3rd row outer hair cell is missing. Supporting cell cytoplasm fills spaces of Nuel. (C) Type I scar 9 hours after treatment. Outer hair cells from all 3 rows are replaced by supporting cells, which fill entire space between tunnel of Corti and Hensen cells. Note that inner hair cell is present and the typical shape of organ of Corti is preserved. (D) Type I scar found nine months after drug treatment. Inner hair cell is present and the distance between Hensen cells and pillar cells is reduced. Magnification: $\times 450$.

modiolus (Fig. 2B). The bridge often contained two parallel bands of actin. The two actin-bands formed a loop around the cuticle-free zone but did not invade it.

Surface view of the organ of Corti five hours after drug administration showed that the reticular lamina in scarring areas became positively labeled for cytokeratins (Fig. 5 A,B). Double-labeling techniques enabled co-localization of actin and cytokeratins (Fig. 5 C,D). The co-localization showed that cytokeratin-positive supporting cells were forming PSs beneath the apical (reticular lamina) portion of hair cells. Vimentin is another IF which has been found in scar-forming cells in certain tissues. At five hours after drug adminis- tration vimentin immunoreactivity was not observed in the scarred area of the reticular lamina (results not shown).

Concomitant with the actin-bridge formation and the appearance of cytokeratins in the scar region, was a gradual disappearance of the original adherens junction of the hair cell from the reticular lamina (Fig. 2C). Nine hours after drug administration, the original adherens junction was absent from most PSs. At this time, surface view of actin-labeled preparations revealed the actinbridge situated in the mid-line between two supporting cells (Fig. 2D). SEM inspection of the scar revealed two supporting cells with protruding ridge in the region of contact between them (Fig. 6). 

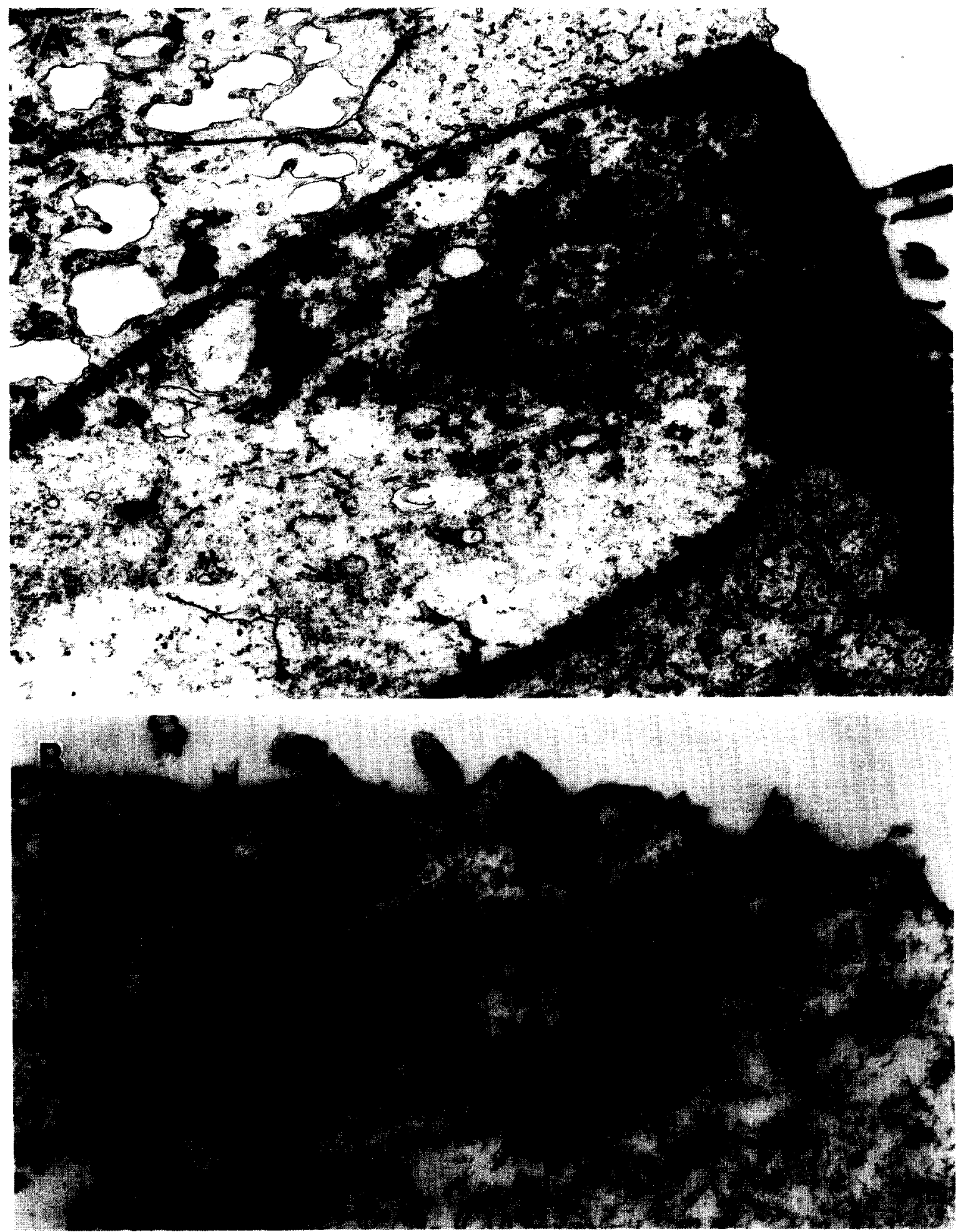

Fig. 4. TEM micrographs of 2 nd row outer hair cell region. (A) 3 hours after insult, spaces of Nuel are obliterated by supporting cells. Cytoplasm of hair and supporting cells appears abnormally vacuolated. Dense substance in cuticular plate is partly missing (arrow) and actin in stereocilia does not look normal. (B) Two supporting cells 9 hours after drug treatment, connected by actin-bridge (arrow) in type $I$ scar. Note discontinuity of lateral membranes of these two cells under the bridge (arrowheads). Magnification: $A=$ $\times 12,000 ; \mathrm{B}=\times 80,000$. 

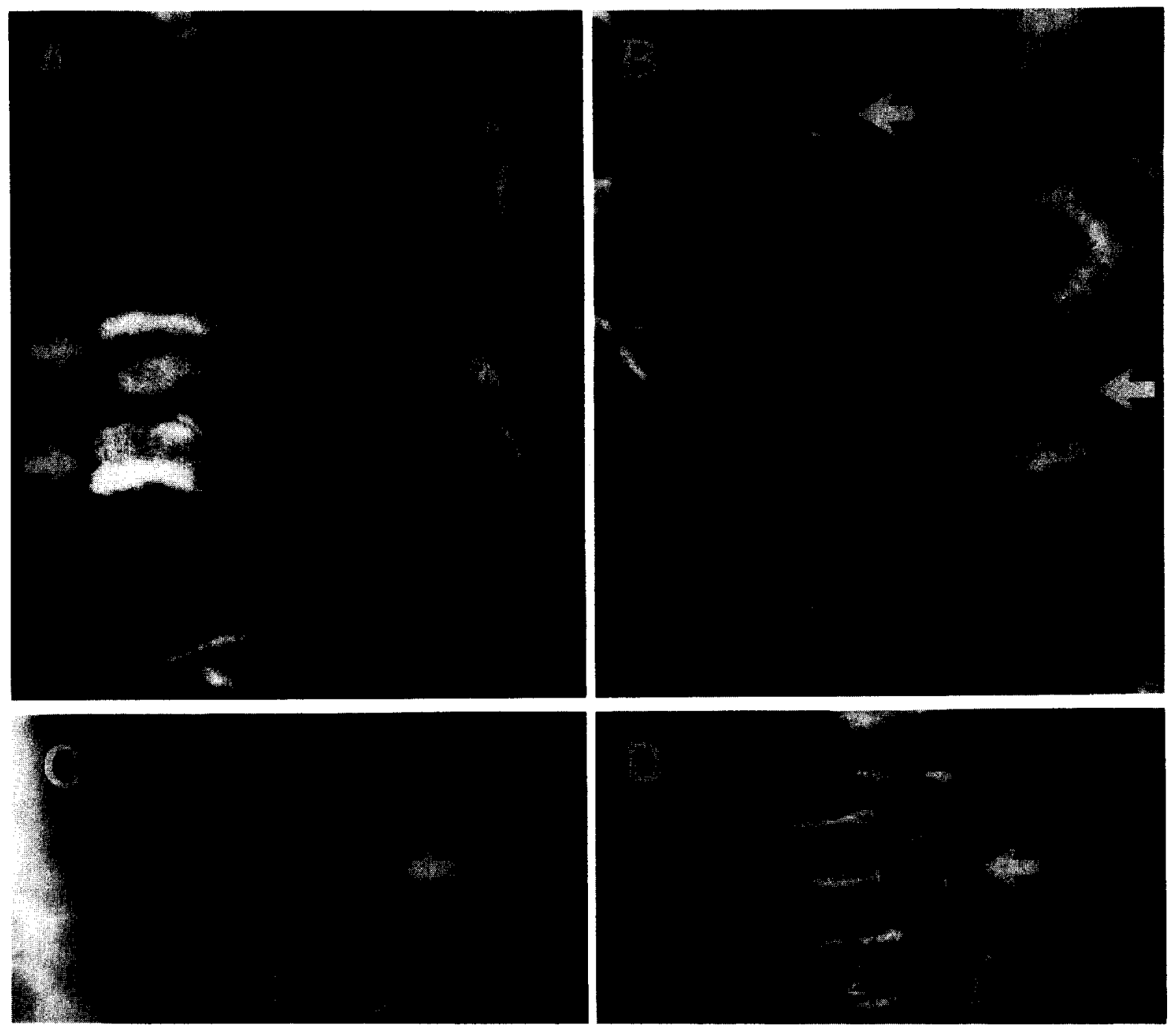

Fig. 5. Whole-mounts of organ of Corti immuno-labeled for cytokeratins (A, B) or double-labeled for actin and cytokeratins (C, D). (A) Apical area of 1 st and 2 nd row outer hair cells $(1,2)$ are devoid of label, while supporting cell surface is positive. Cytokeratin-positive labeling is seen in two scars in 1st row outer hair cells (arrows). (B) Cytokeratin staining in scars (arrows) of 2nd and 3rd row outer hair cells $(2,3)$. (C) Phallacidin labeling showing three rows of outer hair cells $(1,2,3)$ with one cell missing in the 3rd row (arrow). (D) Area corresponding to missing cell in $\mathrm{C}$ stains positive for cytokeratin (arrow). Magnification: $\mathrm{A}$ and $\mathrm{B}=$ $\times 1400 ; \mathrm{C}=\times 800$.

TEM view of a PS showed two supporting cells with an actin bridge at the contact point between them (Fig. 4B). This actin bridge resembled an adherens junction. The lateral membranes of the two supporting cells appeared discontinuous in several places beneath the bridge. LM sections of a region containing scars showed that supporting cells occupied a region previously occupied by the outer hair cells. The inner hair cell in this area was present and the typical height of the organ of Corti was preserved (Fig. 3C).

We define the resulting scar as 'type I' PS. Analysis of SEM preparations (Fig. 6) and histochemically labeled whole-mounts (Figs. 2 and 5) showed that the scar-forming cells for each row of hair cells were invariably the two 'neighbors' (supporting cells) from the same row in the reticular lamina. Thus, first-row outer hair cells were 


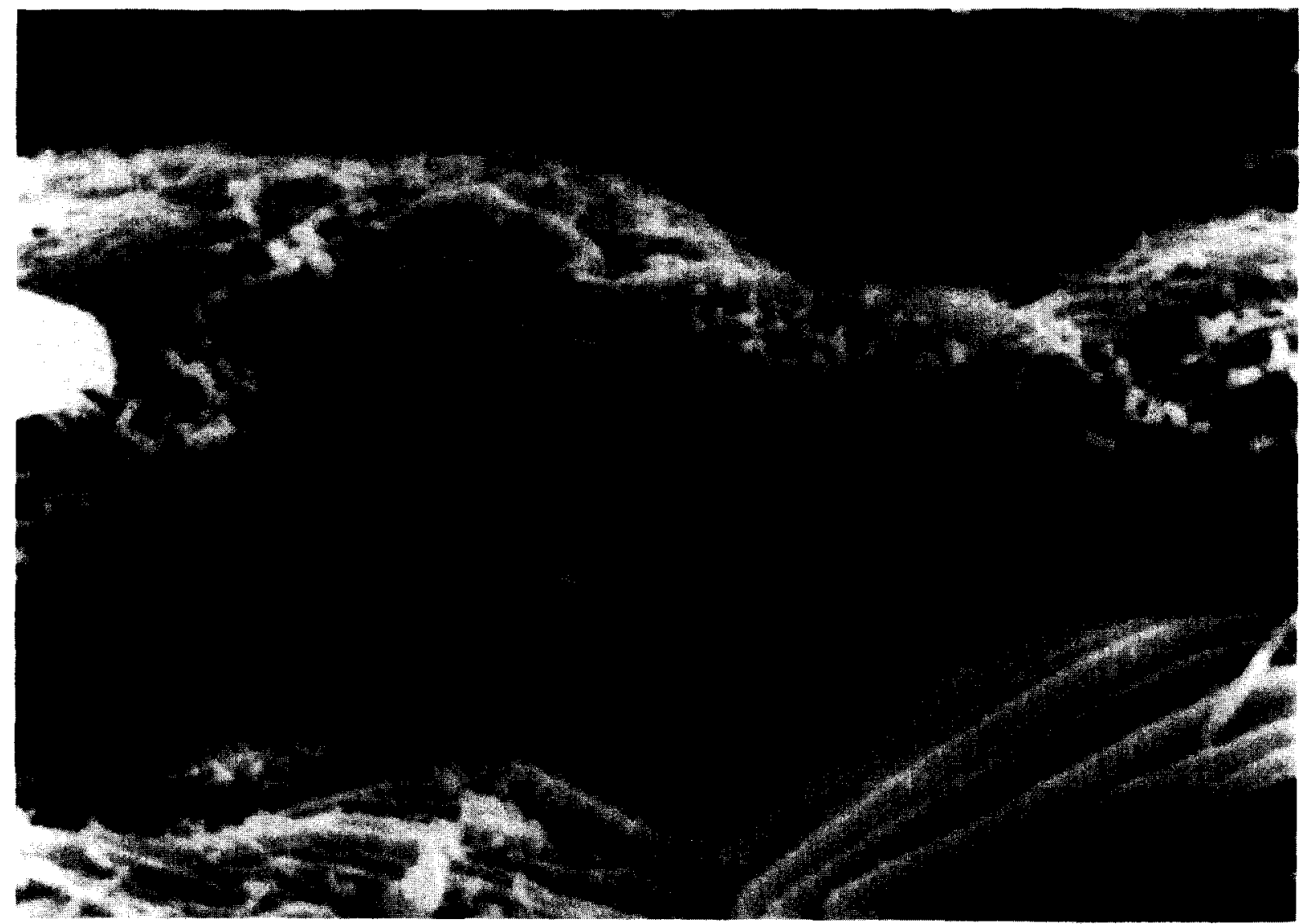

Fig. 6. SEM micrograph of a type I scar. Apical surface of scar-forming cells is covered with microvilli. Protruding ridge is seen in mid-line of contact between two cells (white-arrow). Two hair cells are present in same row, on each side of scar. black-arrow points to stereocilia of a hair cell. Magnification $=\times 13,500$.

replaced through expansion of the outer pillar cells. Second- and third-row outer hair cells were replaced by first- and second-row Deiters cells, respectively.

Type I scars could be found as early as nine hours after administration of the drugs, but some scars appeared to form several weeks after drug administration. Type I PSs were found in animals sacrificed six or nine months after insult, especially in the middle and upper cochlear turns, where PSs appeared in all three rows of outer hair cells (Fig. 3D). In the lower turn, the organ of Corti was degenerated beyond the stage of type I scar. It was collapsed and the basilar membrane was covered by a layer of simple epithelium (results not shown).

Inner hair cells were usually present in regions where type I PSs were seen. In the lower turn of the cochlea type I scars appcared earlier than in the upper turns, but the stages of PS formation and the structure of the mature type I scar were similar in upper and lower cochlear turns. Perforations or discontinuities in the reticular lamina were never observed in this study throughout the process of outer hair cell degeneration and scar formation.

\section{Discussion}

These results provide insight into the mechanism of scarring in the organ of Corti after trauma induced by kanamycin and ethacrynic acid. Three major observations emerge:

a. The process of scar formation temporally coincides with hair cell degeneration.

b. Scar formation is coordinated with degenera- 
tion of the apical hair cell membrane, so that dying hair cells do not leave openings in the reticular lamina.

c. Scar formation involves highly regulated cell expansion, concomitant with reorganization of the microfilament and IF systems.

Scarring associated with hair cell loss in the organ of Corti may be necessary to prevent progressive damage and to preserve residual hearing after partial hair cell loss. This study demonstrates that the cytokeratin-rich cytoplasm of scar-forming cells invades the sub-apical area of degenerating hair cells. As a result, the PS can form prior to degeneration of the apical area. This leaves the reticular lamina intact during the cellular rearrangement, and may prevent leak of fluids across the reticular lamina.

An uninterrupted reticular lamina has been observed in areas where outer hair cells are degenerating (Duvall and Rhodes, 1967; Hawkins, 1973; Brown et al., 1989; McDowell et al., 1989). Preliminary findings on scarring after noise-induced hair cell loss in guinea pigs reveal a scarring pattern very similar to that reported here (Raphael et. al., 1990). It is likely, however, that the mechanism of PS formation may be different, depending on the type of insult. An ototoxic insult induced by neomycin has been shown to result in an irregular scar pattern (Hawkins, 1973). Acoustic overstimulation has been shown to result in perforations of the reticular lamina in chinchillas (Bohne, 1976; Bohne and Rabbitt, 1983). Factors such as the intensity or severity of the insult as well as species specificity may determine the course of PS formation.

The rearrangement of the tissue during PS formation was very orderly. We observed that each dying hair cell is replaced by a scar formed from two supporting cells in the same row. A given supporting cell is therefore capable of forming a PS for its neighboring hair cell on the right, the left, or if necessary on both sides. An efficient spatial and temporal regulation must be active to achieve such an orderly replacement of hair cells by supporting cells. It is possible that degeneration of hair cells and scar formation are two separate, yet related mechanisms, and that one scarring mechanism may be activated by several types of hair cell insults. The scarring process may have evolved to deal with slow hair cell loss due to aging, therefore it is interesting to note that scars form efficiently even after severe insult.

It is important to determine the signal which directs each supporting cell to form a scar. The signal for scarring may be related to some 'point of no return' in the degeneration of the injured hair cell. Possible signals include diffusible substances, with a systemic or local distribution. Alternatively, PS formation could be induced by local interactions between cells or hetween cells and the extracellular matrix. Based on the specificity of the response from supporting cells in the apical junctional domain, we speculate that the most likely site for signalling and regulation is in the apical contact area. The contact between a hair cell and a supporting cell in the apical area features a tight junction and an adherens junctional complex (Gulley and Reese, 1976). The adherens junctional complex provides mechanical stability, surface tension, signalling and regulation of intercellular interactions as well as organization of the microfilament cytoskeleton (see Schliwa, 1986 for a review).

Considering the major changes in the microfilament system during PS formation, we speculate that microfilaments and adherens-type junctions play a major role in the scarring process. Indeed, the actin-rich bridge is among the first observable elements in the scar. Although the bridge can be detected in the region usually occupied by the hair cells, its origin is unknown. The actin bridge may be assembled by the degenerating hair cell. Alternatively, the bridge may constitute the leadingedges of supporting cells which expand and invade the sub-apical area of the hair cell. It is likely that the bridge plays a role in regulating subsequent events in the scarring process. Rapid assembly of the actin-bridge suggests that it contains filaments derived from a pool of depolymerized actin. We speculate that degenerating hair cells play a role during the early stages of scar formation, in organizing and orienting the actin-bridge. More information is needed about the nature of the actin bridge in type I PSs, to find out whether it has the structural characteristics of a true junctional complex, or serves as a passive mechanical scaffolding.

Type I PSs were found as early as nine hours 
after the insult and in animals sacrificed nine months after the insult, suggesting that these scars can be stable for long periods of time. We could not conclude what determines whether a PS will remain at the type I stage or degenerate further. Type I scars were almost always associated with inner hair cell survival, suggesting a direct or indirect association between inner hair cell presence and the stability of the scar. Studies are now underway to assess the process of progressive degeneration and to define the stages during which type I scars disappear and simple flat epithelium replaces the organ of Corti.

Further experiments are necessary to understand why non-mammalian hair cells regenerate (Corwin and Cotanche, 1988; Ryals and Rubel, 1988), while in mammals a scar remains. By comparing avian with mammalian supporting cells, in normal ears as well as after insults, it may be possible to determine the point in evolution at which hair cell regeneration and scar formation diverged from each other.

In conclusion, our results provide preliminary structural and molecular information about the dynamics of scar formation and the role of the scar in the pathophysiology of the cochlea. Major changes were observed in the microfilament system of hair cells and supporting cells during the scarring process. An actin-rich bridge was identified which may provide mechanical support and serve as a template for the scar. The scar-forming cells express cytokeratin-type IFs which may provide further mechanical support to the remaining cells. The continuity of adherens junctional complexes maintains the functional and structural integrity of the reticular lamina. The development of type I scars appears to occur simultaneous with hair cell degeneration. The scarring mechanism appears to be similar in different cochlear regions and it is likely that the same mechanism may regulate scarring after different types of insult to the cochlea.

\section{Acknowledgements}

The authors would like to thank Dr. Joseph Hawkins and Ms Donna Martin for enlightening conversations and critical review of the manuscript. The assistance of Drs. Najaf Gholizadeh
Ganjei, Duane Hartshorn and Elizabeth Plattner is gratefully acknowledged. This work was supported by NIH grant NS 05785 .

\section{References}

Anniko, M., Thornell, L.E. and Virtanen, I. (1987) Cytoskeletal organization of the human inner ear. Acta Otolaryngol. Suppl. 434, 5-76.

Bohne, B.A. (1976) Healing of the Noise Damaged Inner Ear. In: S.K. Hirsh, D.H. Eldredge, I.J. Hirsh and S.R. Silverman (Eds.), Hearing and Davis: Essays Honoring Hallowel Davis, Washington University Press, Saint Louis, MO, pp. 85-96.

Bohne, B.A. and Rabbitt, K.D. (1983) Holes in the reticular lamina after noise exposure: Implication for continuing damage in the organ of Corti. Hear. Res. 11, 41-53.

Brown, A.M., McDowell, B, and Forge, A. (1989) Acoustic distortion products can be used to monitor the effects of chronic gentamicin treatment. Hear. Res, 42, 143-156.

Corwin, J.T. and Cotanche, D.A. (1988) Regeneration of sensory hair cells after acoustic trauma. Science $240,1772-$ 1774.

Cowin, P., Franke, W.W., Grund, C., Kapprell, H.-P. and Kartenbeck, J. (1985) The desmosome-intermediate filament complex. In: G.M. Edelman and J.P. Thiery (Eds.), The cell in contact, Neurosci. Inst. Pub., John Wiley and Sons, New-York. p 427.

Duvall, A.J. III and Rhodes, V.T. (1967) Ultrastructure of the organ of Corti following intermixing of cochlear fluids. Ann, Otol. Rhinol Laryngol. 76, 688-708.

Engström, H., Ades, H.W. and Andersson, A. (1966) Structural pattern of the organ of Corti: a systematic mapping of sensory cells and neural elements. Almquist and Wiksell, Stockholm.

Flock, $\stackrel{\AA}{\AA}$ and Cheung, H. C. (1977) Actin filaments in sensory hairs of inner ear receptor cells. J. Cell Biol. 75, 339-343.

Franke, W.W., Schmid, E., Schiller, D.L., Winter, S., Jarasch, E.D., Moll, R., Denk, H., Jackson, B.W. and Illmensee, K. (1982) Differentiation-related patterns of expression of proteins of intermediate-sized filaments in tissues and cultured cells. Cold Spring Harbor Symp. Quant. Biol. 46, 432-453.

Geiger, B., Avnur, Z., Rinnerthaler, G., Hinssen, H. and Small, V. (1985a) Microfilament organizing centers in areas of cell contact: Cytoskeletal interactions during cell attachment and locomotion. J. Cell Biol. 99, 83-91.

Geiger, B., Avnur, Z., Volberg, T. and Volk, T. (1985b) Molecular domains of adherens junctions. In: G.M. Edelman and J.P. Thiery (Eds.). The cell in contact, Neurosci. Inst. Pub., John Wiley and Sons, New-York, 461-489

Gulley, R. L. and Reese, T. S. (1976) Intercellular junctions in the reticular lamina of the organ of Corti. J. Neurocytol. 5, 479-507.

Hawkins, J.E. (1973) Comparative Otopathology: Aging, Noise, and Ototoxic Drugs. Adv. Oto-Rhino-Laryngol. 20, 125141.

Hawkins, J.E. (1976) Drug Ototoxicity. In: W.D. Keidel and 
W.D. Neff (Eds.), Handbook of Sensory Physiology, Vol V3, p. 707.

Klymkowski, M.W., Bachant, J.B. and Domingo, A. (1989) Functions of intermediate filaments. Cell Motil. 14, 309331.

McDowell, B., Davies, S. and Forge, A (1989) The effect of gentamicin induced hair cell loss on the tight junctions of the reticular lamina. Hear. Res. 40, 221-232.

Osborn, M., Geisler, N., Shaw, G., Sharp, G. and Weber, K. (1982) Intermediate filaments. Cold Spring Harbor Symp. Quant. Biol. 46, 413-430.

Raphael, Y., Marshak, G., Barash, A. and Geiger, B. (1987) Modulation of intermediate filament expression in the developing cochlear epithelium. Differentiation 35, 151-162.

Raphael, Y. and Oesterle, E.C. (1989) The distribution of intermediate filaments in the organ of Corti. Abstr. Assoc. Res. Otolaryngol. St. Petersburg Beach, Florida.

Raphael, Y., Prosen, C.A., Dolan, D.F. and Altschuler, R.A. (1990) Cochlear damage due to high- versus low-frequency noise exposure in the guinea pig. Abstr. Assoc. Res. Otolaryngol. St. Petersburg Beach, Florida.

Ryals, B.M. and Rubel, E.W. (1988) Hair cell regeneration after acoustic trauma in adult Coturnix quail. Science 240 , 1774-1776.

Schliwa, M. (1986) The cytoskeleton: An introductory survey. Springer Verlag, Berlin, Heidelberg, New York.

Slepecky, N. and Chamberlain, S.C. (1982) Distribution and polarity of actin in the sensory hair cells of the chinchilla cochlea. Cell Tissue Res. 224, 15-24.

Small, V., Rinnerthaler, G. and Hinssen, H. (1982) Organization of actin meshworks in cultured cells: the leading edge. Cold Spring Harbor Symp. Quant. Biol. 46, 599-611.

Tilney, L.G. and Saunders, J.C. (1982) Actin filaments, stereocilia, and hair cells of the bird cochlea. I. The length, number, width, and distribution of stereocilia of each hair cell are related to the position of the hair cell on the cochlea. J. Cell Biol. 96, 807-821.

Webster, N. and Webster, D.B. (1981) Spiral ganglion neuron loss following organ of Corti loss: A quantitative study. Brain Res. 212, 17-30.

Wilson, D.W., Plopper, C.G. and Dungworth, D.L. (1984) The responses of the macaque tracheobronchial epithelium to acute ozone injury. A quantitative ultrastructural and autoradiographic study. Am. J. Pathol. 116, 193-206. 